Pesq. Vet. Bras. 29(1):17-24, janeiro 2009

\title{
Hemograma, proteinograma, ionograma e dosagens bioquímicas e enzimáticas de ovinos acometidos por conidiobolomicose no Nordeste do Brasil ${ }^{1}$
}

\author{
Maria do Carmo de S. Batista ${ }^{*}$, Roberto S. de Castro ${ }^{3}$, Eneida W. Rego ${ }^{3}$, \\ Fernando Aécio de A. Carvalho ${ }^{4}$, Silvana Maria M. S. Silva ${ }^{5}$, Cleyton C. D. \\ Carvalho $^{6}$ e Franklin Riet-Correa ${ }^{7}$
}

\begin{abstract}
Batista M.C.S, Castro R.S., Rego E.W., Carvalho A.A., Silva S.M.S., CarvaIho C.D.D. \& Riet-Correa F. 2009. [Hematology and blood biochemistry in sheep with conidiobolomycosis in northeastern Brazil.] Hemograma, proteinograma, ionograma e dosagens bioquímicas e enzimáticas de ovinos acometidos de conidiobolomicose no Nordeste do Brasil. Pesquisa Veterinária Brasileira 29(1):17-24 Departamento de Morfofisiologia Veterinária da Universidade Federal do Piauí, Campus Universitário Ministro Petrônio Portella, s/n, Bairro Ininga, Teresina, PI 64049-450, Brazil. Email: cbatista@ufpi.br

Hematologic values, serum levels of albumin, globulins, total proteins, calcium, phosphorus, magnesium, chloride, urea nitrogen, creatinine, total, direct and indirect bilirrubin, and serum activities of aspartate aminotransferase (AST), alkalin phosphatase (AF) and gama-glutamyltransferase (GGT) were determined in 56 hair sheep with conidiobolomycosis and 371 healthy hair sheep from the same flocks. Sheep with conidiobolomycosis had nonregenerative, normocytic and normochromic anemia, leucocytosis with neutrophilia and increased nutrophil:lymphocyte rate, moderate monocytosis, moderate thrombocytosis, hypoproteinemia (hypoglobulinemia), hypomagnesemia, hypocalcemia and increased values of phosphorus. Serum activities of AST and GGT were increased and serum activity of FA decreased. Serum values of urea and creatinine were within normal values. Hypoglycemia and hyperbilirrubinemia were also observed. These results can be used for experimental studies with the disease, for treatments trials, and to detect early cases of the disease without clinical signs. Otherwise the hematologic and blood biochemistry values of healthy sheep can be used as reference values for hair sheep in the semi-arid region of Brazil.
\end{abstract}

INDEX TERMS: Serum biochemistry, hematology, liver function, renal function, conidiobolomycosis, healthy hair sheep.

\footnotetext{
${ }^{1}$ Recebido em 11 de junho de 2008.

Aceito para publicação em 30 de julho de 2008.

Parte da Tese de Doutorado do primeiro autor apresentada no Programa de Pós-Graduação em Ciência Veterinária (PPGCV), Universidade Federal Rural de Pernambuco (UFRPE).

${ }^{2}$ Departamento de Morfofisiologia Veterinária, Universidade Federal do Piauí (UFPI), Campus Universitário Ministro Petrônio Portella s/ n, Bairro Ininga, Teresina, PI 64049-450, Brasil. *Autor para correspondência: cbatista@ufpi.br

${ }^{3}$ Departamento de Medicina Veterinária, UFRPE, Rua Dom Manuel $\mathrm{s} / \mathrm{n}$, Recife, PE 52171-900, Brasil.

${ }^{4}$ Departamento de Bioquímica e Farmacologia, UFPI, Teresina, PI.

${ }^{5}$ Departamento de Clínica e Cirurgia Veterinária, UFPI, Teresina, PI.

${ }^{6}$ Mestrando do PPGCV, UFRPE, Recife, PE.

${ }^{7}$ Hospital Veterinário, CSTR, Universidade Federal de Campina Grande, Patos, PB 58700-000, Brasil. E-mail: franklin.riet@pq.cnpq.br
}

RESUMO.- Foram realizados eritrogramas, leucogramas, dosagens séricas de proteínas totais, albumina, globulinas, cálcio, fósforo, magnésio, cloretos, uréia, creatinina, bilirrubina total, direta e indireta e atividade sérica de aspartato aminotransferase (AST), fosfatase alcalina (FA) e gamaglutamiltransferase (GGT) de 56 ovinos afetados por conidiobolomicose e de 371 ovinos sadios provenientes dos mesmos rebanhos dos casos da doença. Os resultados revelaram que os ovinos com conidiobolomicose apresentam anemia arregenerativa normocítica normocrômica, leucocitose com neutrofilia e discreto desvio à esquerda regenerativo, com elevação da relação neutrófilo:linfócito, monocitose moderada, trombocitose, hipoproteinemia (hipoglobulinemia), hipomagnesemia, hipocalcemia e eleva- 
ção dos teores de fósforo. As atividades séricas de AST e GGT estavam aumentadas e as de FA diminuídas. Não houve alteração nos níveis de uréia e creatinina, mas ocorreu hipoglicemia e hiperbilirrubinemia. Estes resultados podem ser utilizados para estudos experimentais da doença, em ensaios com tratamentos e para identificar casos precoces da enfermidade que não apresentem sinais clínicos. Além disso, os valores encontrados em 371 ovinos deslanados hígidos podem ser utilizados como valores referenciais para este tipo de ovinos na região semiárida do Brasil.

TERMOS DE INDEXAÇÃO: Patologia clínica, células sanguíneas, enzimas hepáticas, uréia, creatinina, bilirrubina sérica, conidiobolomicose, ovinos.

\section{INTRODUÇÃO}

Conidiobolomicose é um tipo de zigomicose causada pelo fungo Conidiobolus spp., da ordem Entomophtorales, classe Zygomycetes (Lacaz 1981), cujas principais espécies são Conidiobolus coronatus, $C$. incongrus e $C$. lamprageus. (Zamos et al. 1996, Morris et al. 2001). Já foi descrita em eqüinos (Mendoza \& Alfaro 1985), cães (Bauer et al. 1997), ovinos (Carrigan et al. 1992, Ketterer et al. 1992), muares (Johnston et al. 1967), golfinhos (Medway 1980), macacos (Roy \& Cameron 1972), Ihamas (Moll et al. 1992, French \& Ashworth 1994) e cervos (Stephens \& Gibson 1997). Há, também, relatos de sua ocorrência em humanos no Brasil (Souza Filho et al. 1992, Tadano et al. 2005) e em outros países (King \& Jong 1976).

Em humanos as infecções por Entomophtorales têm sido associadas a situações de estresse e queda de imunidade, porém, em animais não há clareza sobre esse aspecto (Rippon 1988, Prabhu \& Patel 2004).

No Brasil a doença é freqüente em ovinos do Estado do Piauí (Silva et al. 2007a,b) e tem sido diagnosticada em outros estados incluindo Paraíba (Riet-Correa et al. 2008), Mato Grosso (Arruda et al. 2007) e Santa Catarina (Furlan et al. 2007). No Piauí o agente causal da enfermidade foi inicialmente identificado como $C$. coronatus (Silva et al. 2007ab). Provoca apatia, anorexia, rinite granulomatosa afetando a região etmoidal e regiões adjacentes, descarga nasal serosa, catarral e/ou sanguinolenta, elevação das freqüências respiratória e cardíaca, respiração ruidosa, podendo produzir assimetria crâniofacial, exoftalmia e pneumonia, culminando com a morte em $100 \%$ dos casos (Silva et al. 2007ab).

Os dados da literatura acerca dos achados laboratoriais desta enfermidade são raros. Em cães, foi relatado um aumento nos teores de AST, porém as mensurações foram procedidas após o início do tratamento com itraconazole e essa alteração foi atribuída aos efeitos da terapia (Bauer et al. 1997).

Considerando tratar-se de doença importante, sem prévia descrição dos seus aspectos laboratoriais, este trabalho objetivou descrever a patologia clínica em ovinos acometidos, comparando os dados com os de animais hígidos provenientes dos mesmos rebanhos.

\section{MATERIAL E MÉTODOS}

O trabalho foi desenvolvido nos anos de 2002-2004, utilizandose 56 ovinos portadores de manifestações clínicas de conidiobolomicose, posteriormente confirmada laboratorialmente (Silva et al. 2007ab), originarários de 23 rebanhos de propriedades situadas em 11 municípios piauienses.

Foram feitas avaliações clínicas nos animais afetados e, para fins comparativos, foram realizadas, também, nos animais hígidos oriundos dos mesmos rebanhos, incluindo-se exames coprológicos, pela técnica de Gordon \& Whitlock modificada (McMaster), a fim de quantificar opg (Ueno \& Gonçalves 1998). Foram considerados saudáveis os animais que apresentaram boas condições à inspeção clínica, parâmetros de temperatura, freqüências respiratória e cardíaca dentro da normalidade e carga parasitária inferior a 500opg.

A amostra experimental foi representada pelo total de ovinos atendidos vivos no Hospital Veterinário da Universidade Federal do Piauí (UFPI) com as manifestações clínicas da doença, nos anos de 2002-2004. O número de animais sadios utilizado foi calculado segundo Berquó et al. (1981) e Guedes \& Guedes (1988), variando de $20 \%$ nos rebanhos com até 50 animais a $5 \%$, nos rebanhos com mais de 400 ovinos.

A divisão em grupos levou em conta o critério da idade, estimada através da arcada dentária com base na substituição dos incisivos (Pinheiro Júnior 1973), constituindo-se quatro grupos, em cada estado sanitário, sadios e doentes, conforme o Quadro 1.

\section{Quadro 1. Divisão dos ovinos em grupos, por faixa etária} estimada pela arcada dentária

\begin{tabular}{|c|c|c|c|c|c|}
\hline Grupos & $\begin{array}{l}\text { Situação da ar- } \\
\text { cada dentária }\end{array}$ & $\begin{array}{c}\text { Idade } \\
\text { estimada }\end{array}$ & $\begin{array}{l}\text { Estado s } \\
\text { Doentes }\end{array}$ & $\frac{\text { sanitário }}{\text { Sadios }}$ & $\begin{array}{c}\text { Total } \\
\text { por grupo } \\
\end{array}$ \\
\hline $\mathrm{G}-1$ & $\begin{array}{l}\text { Nenhuma muda } \\
\text { efetivada (dente } \\
\text { de leite) }\end{array}$ & Menor que 1 ano & 17 & 84 & 101 \\
\hline G-2 & $\begin{array}{l}\text { Substituição das } \\
\text { pinças e dos pri- } \\
\text { meiros médios }\end{array}$ & $\begin{array}{l}\text { Maior ou igual a } \\
1 \text { e menor que } 3 \\
\text { anos }\end{array}$ & 18 & 92 & 110 \\
\hline G-3 & $\begin{array}{l}\text { Substituição dos } \\
\text { segundos médi- } \\
\text { os e dos cantos } \\
\text { (boca cheia) }\end{array}$ & $\begin{array}{l}\text { Maior ou igual a } \\
3 \text { e menor ou } \\
\text { igual a } 5 \text { anos }\end{array}$ & 10 & 91 & 101 \\
\hline G-4 & $\begin{array}{l}\text { Rasamento de } \\
\text { dentes }\end{array}$ & Maiorque 5 anos & 11 & 104 & 115 \\
\hline \multicolumn{2}{|c|}{ Total geral } & & 56 & 371 & 427 \\
\hline
\end{tabular}

As colheitas de sangue para hemograma foram feitas por venopunção jugular, usando-se frascos de colheita à vácuo contendo EDTA-sódico e os hemogramas foram processados pelo método da contagem automática de células, utilizando-se aparelho VET ABC-TM Micros 60, com cartão ABC Smart CARD "sheep". A dosagem de hemoglobina foi processada por espectrofotometria e a determinação do volume globular pelo método padronizado pelo Comitê Internacional de Padronização em Hematologia. As determinações dos índices eritrocitários, ou seja, volume corpuscular médio (VCM), hemoglobina corpuscular média (HCM) e concentração hemoglobínica corpuscular média ( $\mathrm{CHCM}$ ) foram feitas, também, por automação, pela aplicação matemática das fórmulas internacionalmente consagradas. A contagem diferencial de leucócitos foi procedida por observação ao microscópio de 100 
células da série branca, nos esfregaços de sangue corados por panótico rápido (Instant-Prov, Newprov) (Jain 1993, Kerr 2003).

Para estabelecer o perfil protéico e o ionograma, as colheitas de sangue foram feitas por venopunção jugular, usando-se francos de colheita à vácuo sem anticoagulante, envoltos em papel alumínio para protegê-las da ação da luz e os soros foram obtidos por centrifugação. Para determinar o perfil protéico realizaram-se as dosagens de proteínas totais (PT), albuminas e globulinas. As PT foram mensuradas pelo método do "biureto", albuminas pelo "verde de bromocresol", seguindo-se, em ambos os casos, as indicações do fabricante (Lab-test Diagnóstica). As globulinas foram encontradas pela diferença matemática entre os valores de PT e albuminas. A relação albumina/ globulinas $(A: G)$ foi obtida através de cálculo matemático (Kaneko et al. 1997).

O ionograma constou da mensuração dos eletrólitos: cálcio, fósforo, magnésio e cloretos. As dosagens de cálcio tiveram por princípio a sua complexação com a púrpura de ftaleína, em meio alcalino; as determinações de fósforo basearam-se em sua reação com molibdênio, em meio ácido; as de magnésio fundamentaram-se em sua reação com o magnon sulfonado, em meio alcalino; e as de cloretos basearam-se nas reações com tiocianato de mercúrio e íons férricos. Os procedimentos para dosar estes elementos foram os explicitados nos kits comerciais Lab-Test.

As dosagens bioquímicas foram realizadas mediante espectrofotometria utilizando-se os Kits analíticos "Lab-test" (Labtest Diagnóstica S.A.). Para a determinação de glicose utilizou-se plasma obtido de sangue total colhido com inibidor de glicólise e a metodologia Trinder. O procedimento utilizado para as determinações dos teores de uréia foi a Urease-Labtest e de bilirrubina foi a metodologia Sims-Hom, estando as amostras protegidas da luz, mediante o envoltório dos frascos em papel alumínio. A bilirrubina indireta foi obtida por diferença entre o valor da total e o da direta (Lima et al. 2001). As dosagens de creatinina foram realizadas segundo a metodologia Labtest que se fundamenta na reação desta com a solução de picrato, em meio alcalino.

As dosagens de fosfatase alcalina (FA) foram procedidas por método cinético de tempo fixo, denominado Roy modificado. As análises de gama-glutamiltransferase (gama-GT), foram efetivadas pelo Szasz modificado e as de aspartato-aninotranferase pela metodologia Reitman e Frankel, com o kit "transaminase oxalacética". Em todas elas, as amostras foram também protegidas da luz e analisadas à temperatura de $25^{\circ} \mathrm{C}$, seguindo-se os padrões recomendados pela International Federation of Clinical Chemistry (Moss \& Handerson 1998).

Utilizou-se delineamento inteiramente casualizado, no modelo de blocos ao acaso, disposto em ensaio fatorial do tipo $2 \times 4$, ou seja, dois estados sanitários (animais sadios e doentes) por 4 faixas etárias (Quadro 1). Realizou-se análise de variância pelo Teste " $F$ " de Fisher, a fim de verificar diferenças entre tratamentos, adotando-se o Teste de Student-Newman-Keuls (SNK) para a comparação de médias (Sampaio 1998).

\section{RESULTADOS}

A epidemiologia, sinais clínicos e a patologia dos casos de conidiobolomicose incluídos neste trabalho foram descritos por Silva et al. (2007ab). Dos 56 ovinos afetados, 23 eram machos e 33 fêmeas. As faixas etárias variaram de oito meses a mais de cinco anos e tanto animais de raça pura (principalmente Santa Inês e Morada Nova) quanto mestiços foram afetados. Além dos sinais clínicos descritos anteriormente ocorreu aumento das freqüências respiratória e cardíaca (Quadros 2 e 3). Havia respiração ruidosa (estridor respiratório), muitas vezes bifásica,

Quadro 2. Valores médios de freqüência respiratória de ovinos sadios e portadores de conidiobolomicose no Estado do Piauí, nos anos de 2002-2004, segundo a faixa etária

\begin{tabular}{|c|c|c|c|c|c|}
\hline \multirow[t]{2}{*}{$\begin{array}{l}\text { Estado } \\
\text { sanitário }\end{array}$} & \multicolumn{4}{|c|}{$\begin{array}{l}\text { Grupos por faixa etária (número de } \\
\text { ciclos por minuto) }\end{array}$} & \multirow[t]{2}{*}{ Médias } \\
\hline & $\mathrm{G} 1^{*}$ & G2 & G3 & G4 & \\
\hline & 41 & 4 & 4 & 39 & 40 \\
\hline Doer & 46,0 & 43,3 & 53,5 & 42,364 & $46,310^{a}$ \\
\hline Média & $43,604^{\mathrm{A}}$ & $42,688^{\mathrm{A}}$ & $46,792^{A}$ & $41,994^{\mathrm{A}}$ & - \\
\hline
\end{tabular}

* G1= menores do que 1 ano; G2 = de 1-3 anos; G3 = de 3-5 anos; G4 = mais de 5 anos. Médias na mesma coluna, seguidas da mesma letra minúscula, não diferem entre si pelo teste SNK $(P>0,05)$. Médias, na mesma linha, seguidas da mesma letra maiúscula, não diferem entre si pelo teste SNK $(P>0,05)$.

Quadro 3. Valores médios de freqüência cardíaca de ovinos sadios e portadores de conidiobolomicose no Estado do Piauí, nos anos de 2002-2004, segundo a faixa etária

\begin{tabular}{lccccc}
\hline \multirow{2}{*}{$\begin{array}{c}\text { Estado } \\
\text { sanitário }\end{array}$} & \multicolumn{4}{c}{$\begin{array}{c}\text { Grupos por faixa etária (batimentos } \\
\text { por minuto) }\end{array}$} \\
\cline { 2 - 5 } & $\mathrm{G} 1^{*}$ & $\mathrm{G} 2$ & $\mathrm{G} 3$ & $\mathrm{G} 4$ & \\
\hline Sadios $(\mathrm{n}=115)$ & $82,417^{\mathrm{Ab}}$ & $83,741^{\mathrm{Aa}}$ & $82,167^{\mathrm{Ab}}$ & $80,353^{\mathrm{Ab}}$ & 82,171 \\
Doentes $(\mathrm{n}=56)$ & $102,467^{\mathrm{Aa}}$ & $96,063^{\mathrm{Aa}}$ & $109,400^{\mathrm{Aa}}$ & $130,727^{\mathrm{Aa}}$ & 109,664 \\
Médias & 99,442 & 89,902 & 95,784 & 105,540 & -
\end{tabular}

* G1= menores do que 1 ano; G2 = de 1-3 anos; G3 = de 3-5 anos; G4 = mais de 5 anos. Médias na mesma linha, seguidas da mesma letra maiúscula, não diferem entre si pelo teste SNK $(P>0,05)$. Médias, na mesma coluna, seguidas da mesma letra minúscula, não diferem entre si pelo teste SNK $(P>0,05)$.

Quadro 4. Valores globais dos eritrogramas de ovinos sadios e portadores de conidiobolomicose no Estado do Piauí, nos anos de 2002-2004, segundo a faixa etária

\begin{tabular}{|c|c|c|c|c|c|c|}
\hline $\begin{array}{l}\text { Tratamentos } \\
\text { (amostra) }\end{array}$ & $\begin{array}{l}\text { Eritrócitos } \\
\left(\mathrm{n}^{\circ} \times 10^{6} / \mu \mathrm{l}\right. \\
\text { de san gue) }\end{array}$ & $\begin{array}{c}\text { Hemo- } \\
\text { globina } \\
(\mathrm{g} / \mathrm{dl})\end{array}$ & $\begin{array}{l}\text { Hema- } \\
\text { tócrito } \\
(\%)\end{array}$ & $\begin{array}{l}\text { VCM } \\
f l\end{array}$ & $\begin{array}{c}\mathrm{HCM} \\
(\mathrm{pg})\end{array}$ & $\begin{array}{c}\mathrm{CHCM} \\
(\%)\end{array}$ \\
\hline $\begin{array}{l}\text { Sadios G1* } \\
\quad(n=84)\end{array}$ & 8,831 & 9,053 & 27,620 & 31,276 & 10,251 & 32,777 \\
\hline $\begin{array}{c}\text { Sadios G2 } \\
\quad(n=92)\end{array}$ & 9,201 & 9,371 & 28,607 & 31,091 & 10,185 & 32,758 \\
\hline $\begin{array}{c}\text { Sadios G3 } \\
\quad(n=91)\end{array}$ & 8,742 & 8,980 & 27,616 & 31,590 & 10,272 & 32,517 \\
\hline $\begin{array}{l}\text { Sadios G4 } \\
(n=104)\end{array}$ & 9,456 & 9,560 & 29,668 & 31,375 & 10,110 & 32,223 \\
\hline $\begin{array}{c}\text { Doentes } G \\
(n=17)\end{array}$ & 7,436 & 8,163 & 22,681 & 30,502 & 10,978 & 35,990 \\
\hline $\begin{array}{c}\text { Doentes G2 } \\
(n=18)\end{array}$ & 7,359 & 7,888 & 21,473 & 29,179 & 10,719 & 36,734 \\
\hline $\begin{array}{l}\text { Doentes G3 } \\
\quad(n=10)\end{array}$ & 6,655 & 7,952 & 19,550 & 29,376 & 11,949 & 40,675 \\
\hline $\begin{array}{c}\text { Doentes G4 } \\
(n=11)\end{array}$ & 9,386 & 9,827 & 28,291 & 30,142 & 10,470 & 34,735 \\
\hline
\end{tabular}


Quadro 5. Valores médios dos eritrócitos, hemoglobina e hematócrito de ovinos sadios e portadores de conidioboIomicose no Estado do Piauí, nos anos de 2002-2004, segundo a faixa etária

\begin{tabular}{|c|c|c|c|c|c|c|}
\hline & \multirow{2}{*}{$\begin{array}{c}\text { Estado } \\
\text { Sanitário }\end{array}$} & \multicolumn{4}{|c|}{ Grupos por faixa etária } & \multirow[t]{2}{*}{ Médias } \\
\hline & & $\mathrm{G} 1^{*}$ & G2 & G3 & G4 & \\
\hline $\begin{array}{l}\text { Eritrócitos } \\
\left(n^{0} \times 10^{6}\right.\end{array}$ & $\begin{array}{l}\text { Sadios } \\
(n=371)\end{array}$ & $8,831^{\mathrm{Ba}}$ & $9,201^{\mathrm{Aba}}$ & $8,742^{\mathrm{Ba}}$ & $456^{\mathrm{Aa}}$ & \\
\hline \multirow[t]{2}{*}{$\begin{array}{l}\text { por } \mu L t \\
\text { de sangue) }\end{array}$} & $\begin{array}{l}\text { Doentes } \\
(n=56)\end{array}$ & $7,436^{\mathrm{Abb}}$ & $7,359 \mathrm{ABb}$ & $655^{\mathrm{Bb}}$ & $\mathrm{Aa}$ & \multirow[t]{2}{*}{7,709} \\
\hline & & 8,1 & 8,28 & 7,6 & 9,4 & \\
\hline $\begin{array}{l}\text { Hemoglobina } \\
\left(n^{0} \times 10^{6}\right.\end{array}$ & $\begin{array}{l}\text { a Sadios } \\
\quad(n=371)\end{array}$ & $9,053^{\mathrm{Ba}}$ & 9,371 & $8,980^{\mathrm{Ba}}$ & $9,560^{A a}$ & 9,2 \\
\hline \multirow[t]{2}{*}{$\begin{array}{l}\text { por } \mu \mathrm{Lt} \\
\text { de sangue) }\end{array}$} & $\begin{array}{l}\text { Doentes } \\
(n=56)\end{array}$ & $8,163^{A b}$ & $7,888^{A b}$ & $7,952^{A b}$ &, $827^{\mathrm{Aa}}$ & 8,45 \\
\hline & Mé & 8, & & 8, & & \\
\hline $\begin{array}{l}\text { Hematócrito } \\
\left(n^{\circ} \times 10^{6}\right.\end{array}$ & $\begin{array}{l}\text { Sadios } \\
(n=371)\end{array}$ & $27,620^{\mathrm{Ba}}$ & $28,607^{\mathrm{Aba}}$ & $27,616^{\mathrm{Ba}}$ & 29,668 Aa & \\
\hline \multirow[t]{2}{*}{$\begin{array}{l}\text { por } \mu \mathrm{Lt} \\
\text { de sangue) }\end{array}$} & $\begin{array}{c}\text { Doentes } \\
(n=56)\end{array}$ & $22,681^{A B b}$ & $21,473^{A B b}$ & $19,550^{\mathrm{Bb}}$ & $28,291 \mathrm{Aa}$ & \\
\hline & Médias & 25,151 & 25,040 & 23,583 & 28,980 & \\
\hline
\end{tabular}

* $\mathrm{G} 1=$ menores do que 1 ano; G2 = de 1-3 anos; G3 = de 3-5 anos; G4 $=$ mais de 5 anos. Médias na mesma linha, seguidas da mesma letra maiúscula, não diferem entre si pelo teste SNK $(P>0,05)$. Em cada parâmetro avaliado, médias, na mesma coluna, seguidas da mesma letra minúscula, não diferem entre si pelo teste SNK $(P>0,05)$.

caracterizada por fase inspiratória prolongada e, em $37,5 \%$ dos casos, havia ruídos pulmonares (estertores crepitantes e sibilos) sugestivos de broncopneumonia.

\section{Hemograma}

Os valores médios gerais do eritrograma de ovinos integrantes deste experimento estão apresentados no Quadro 4. Os valores de eritrócitos, hemoglobina e hematócrito dos ovinos sadios e portadores de conidiobolomicose, de diferentes faixas etárias, encontram-se no Quadro 5.
Os resultados dos leucogramas, em valores médios, estão apresentados no Quadro 6. Os resultados da contagem total de leucócitos, contagem diferencial de leucócitos e plaquetas constam no Quadro 7. Alguns animais doentes do grupo G3, sobretudo os portadores de pneumonia, desenvolveram discreta eosinofilia.

\section{Proteinograma}

Os resultados das determinações de proteínas totais, albuminas e globulinas apresentam-se no Quadro 8. O cálculo da relação $A: G$, procedido a partir das médias gerais dos grupos, apresentou os seguintes resultados: sadios $\mathrm{G} 1=0,726$; sadios $\mathrm{G} 2=0,870$; sadios $\mathrm{G} 3=0,713$; sadios $\mathrm{G} 4=0,702$; doentes $\mathrm{G} 1=0,821$; doentes $\mathrm{G} 2=0,958$; doentes $\mathrm{G} 3=0,797$ e doentes $\mathrm{G} 4=0,857$. A relação média geral para os animais sadios foi de 0,753 e para os enfermos foi de 0,858 .

\section{lonograma}

Os resultados das determinações de magnésio, cálcio, fósforo e cloretos apresentam-se no Quadro 9.

\section{Parâmetros bioquímicos e enzimáticos}

Os resultados das dosagens de glicose, uréia, creatinina, bilirrubina total, bilirrubina indireta, bilirrubina direta, aspartato aminotransferase, fosfatase alcalina e gama-glutamiltransferase por estado sanitário e por grupo de animais, estão sumarizados nos Quadros 10 e 11 .

\section{DISCUSSÃO}

Analisando-se os dados do eritrograma (Quadro 5) constata-se que os animais portadores de conidiobolomicose apresentaram redução significativa nos valores de hemácias, hemoglobina e hematócrito, gerando um quadro de anemia, o qual pode ter ser sido desencadeado

Quadro 6. Leucogramas de ovinos sadios e portadores de conidiobolomicose no Estado do Piauí nos anos de 2002-2004, segundo a faixa etária

\begin{tabular}{|c|c|c|c|c|c|c|c|}
\hline \multirow{2}{*}{$\begin{array}{c}\text { Tratamentos } \\
\text { (amostra) }\end{array}$} & \multirow{2}{*}{$\begin{array}{l}\text { Leucócitos } \\
\text { (no médio } \\
\text { por } \mathrm{ml} \text { ) }\end{array}$} & \multicolumn{4}{|c|}{ Polimorfonucleares } & \multicolumn{2}{|c|}{ Mononucleares } \\
\hline & & $\begin{array}{l}\text { Bastonetes } \\
\text { VA (VR) }\end{array}$ & $\begin{array}{l}\text { Segmentados } \\
\text { VA (VR) }\end{array}$ & $\begin{array}{c}\text { Eosinófilos } \\
\text { VA (VR) }\end{array}$ & $\begin{array}{l}\text { Basófilos } \\
\text { VA (VR) }\end{array}$ & $\begin{array}{l}\text { Linfócitos } \\
\text { VA (VR) }\end{array}$ & $\begin{array}{l}\text { Monócitos } \\
\text { VA (VR) }\end{array}$ \\
\hline $\begin{array}{l}\text { Sadios } \mathrm{G} 1^{*} \\
\quad(\mathrm{n}=84)\end{array}$ & 7375 & $\begin{array}{c}1,77 \\
(0,024 \%)\end{array}$ & $\begin{array}{c}2519,52 \\
(34,163 \%)\end{array}$ & $\begin{array}{c}319,26 \\
(4,329 \%)\end{array}$ & $\begin{array}{c}6,27 \\
(0,085 \%)\end{array}$ & $\begin{array}{c}4433,78 \\
(60,119 \%)\end{array}$ & $\begin{array}{c}98,31 \\
(1,333 \%)\end{array}$ \\
\hline $\begin{array}{l}\text { Sadios G2 } \\
\quad(n=92)\end{array}$ & 7432 & $\begin{array}{c}2,30 \\
(0,031 \%)\end{array}$ & $\begin{array}{c}2438,59 \\
(32,812 \%)\end{array}$ & $\begin{array}{c}295,64 \\
(3,978 \%)\end{array}$ & $\begin{array}{c}4,83 \\
(0,065 \%)\end{array}$ & $\begin{array}{c}4355,00 \\
(61,289 \%)\end{array}$ & $\begin{array}{c}70,08 \\
(0,943 \%)\end{array}$ \\
\hline $\begin{array}{l}\text { Sadios G3 } \\
\quad(n=91)\end{array}$ & 7046 & $\begin{array}{c}1,48 \\
(0,021 \%)\end{array}$ & $\begin{array}{c}2441,58 \\
(34,652 \%)\end{array}$ & $\begin{array}{c}291,63 \\
(4,139 \%)\end{array}$ & $\begin{array}{c}6,97 \\
(0,099 \%)\end{array}$ & $\begin{array}{c}4255,91 \\
(59,976 \%)\end{array}$ & $\begin{array}{c}63,13 \\
(0,896 \%)\end{array}$ \\
\hline $\begin{array}{l}\text { Sadios G4 } \\
(n=104)\end{array}$ & 7084 & $\begin{array}{c}4,18 \\
(0,059 \%)\end{array}$ & $\begin{array}{c}2491,65 \\
(35,1730 \%)\end{array}$ & $\begin{array}{c}398,97 \\
(5,632 \%)\end{array}$ & $\begin{array}{c}5,60 \\
(0,79 \%)\end{array}$ & $\begin{array}{c}4,105,60 \\
(57,956 \%)\end{array}$ & $\begin{array}{c}56,74 \\
(0,801 \%)\end{array}$ \\
\hline $\begin{array}{c}\text { Doentes } G \\
(n=17)\end{array}$ & 13850 & $\begin{array}{c}58,03 \\
(0,419 \%)\end{array}$ & $\begin{array}{c}8387,01 \\
(60,556 \%)\end{array}$ & $\begin{array}{c}519,37 \\
(3,750 \%)\end{array}$ & $\begin{array}{c}5,40 \\
(0,039 \%)\end{array}$ & $\begin{array}{c}4842,79 \\
(34,966 \%)\end{array}$ & $\begin{array}{c}275,62 \\
(1,990 \%)\end{array}$ \\
\hline $\begin{array}{l}\text { Doentes G2 } \\
\quad(n=18)\end{array}$ & 12,780 & $\begin{array}{c}51,89 \\
(0,406 \%)\end{array}$ & $\begin{array}{c}7156,93 \\
(56,001 \%)\end{array}$ & $\begin{array}{c}573,95 \\
(4,491 \%)\end{array}$ & $\begin{array}{c}12,65 \\
(0,099 \%)\end{array}$ & $\begin{array}{c}4502,52 \\
(35,231 \%)\end{array}$ & $\begin{array}{c}417,01 \\
(3,263 \%)\end{array}$ \\
\hline $\begin{array}{l}\text { Doentes G3 } \\
\quad(n=10)\end{array}$ & 14,520 & $\begin{array}{c}58,08 \\
(0,400 \%)\end{array}$ & $\begin{array}{c}8791,86 \\
(60,550 \%)\end{array}$ & $\begin{array}{c}1141,13 \\
(7,859 \%)\end{array}$ & $\begin{array}{c}10,02 \\
(0,069 \%)\end{array}$ & $\begin{array}{c}4352,52 \\
(29,976 \%)\end{array}$ & $\begin{array}{c}231,74 \\
(1,596 \%)\end{array}$ \\
\hline $\begin{array}{c}\text { Doentes G4 } \\
\quad(n=11)\end{array}$ & 13,400 & $\begin{array}{c}16,21 \\
(0,121 \%)\end{array}$ & $\begin{array}{c}8598,91 \\
(64,171 \%)\end{array}$ & $\begin{array}{c}482,00 \\
(3,597 \%)\end{array}$ & $\begin{array}{c}6,97 \\
(0,052 \%)\end{array}$ & $\begin{array}{c}3973,23 \\
(29,651 \%)\end{array}$ & $\begin{array}{c}273,49 \\
(2,041 \%)\end{array}$ \\
\hline
\end{tabular}

* $\mathrm{G} 1$ = menores do que 1 ano; G2 = de 1-3 anos; G3 = de 3-5 anos; G4 = mais de 5 anos; VA = valor absoluto;

$\mathrm{VR}=$ valor relativo . 
Quadro 7. Leucócitos, neutrófilos bastonetes, neutrófilos segmentados, eosinófilos, linfócitos, monócitos e plaquetas de ovinos sadios e portadores de conidiobolomicose no Estado do Piauí, nos anos de 2002-2004, segundo a faixa etária

\begin{tabular}{|c|c|c|c|c|c|c|}
\hline & \multirow{2}{*}{$\begin{array}{c}\text { Estado } \\
\text { sanitário }\end{array}$} & \multicolumn{4}{|c|}{ Grupos por faixa etária* $^{*}$} & \multirow[t]{2}{*}{ Médias } \\
\hline & & G1 & G2 & G3 & G4 & \\
\hline $\begin{array}{l}\text { Leucócitos } \\
\text { (valores médios } \\
\text { por } \mu \text { l de sangue) }\end{array}$ & $\begin{array}{l}\text { Sadios }^{* *} \\
\text { Doentes } \\
\text { Médias }\end{array}$ & $\begin{array}{c}7375 \\
13850 \\
10613^{A}\end{array}$ & $\begin{array}{c}7432 \\
12780 \\
10106^{A}\end{array}$ & $\begin{array}{c}7046 \\
14520 \\
10783^{A}\end{array}$ & $\begin{array}{c}7084 \\
13400 \\
10242^{A}\end{array}$ & $\begin{array}{c}7234^{b} \\
13638^{a} \\
-\end{array}$ \\
\hline $\begin{array}{l}\text { Neutrófilos bastonetes } \\
\text { (valores absolutos mé- } \\
\text { dios por } \mu \text { l de sangue) }\end{array}$ & $\begin{array}{l}\text { Sadios }^{* *} \\
\text { Doentes } \\
\text { Médias }\end{array}$ & $\begin{array}{c}1,770 \\
58,031 \\
29,900^{A}\end{array}$ & $\begin{array}{c}2,304 \\
51,887 \\
27,095^{\mathrm{A}}\end{array}$ & $\begin{array}{c}1,480 \\
58,080 \\
29,780^{A}\end{array}$ & $\begin{array}{c}4,179 \\
16,214 \\
10,195^{\mathrm{A}}\end{array}$ & $\begin{array}{c}2,433^{a} \\
46,053^{b} \\
-\end{array}$ \\
\hline $\begin{array}{l}\text { Neutrófilos segmentados } \\
\text { (valores absolutos mé- } \\
\text { dios por } \mu \text { l de sangue) }\end{array}$ & $\begin{array}{l}\text { Sadios }^{* \star} \\
\text { Doentes } \\
\text { Médias }\end{array}$ & $\begin{array}{c}2519,521 \\
8397,006 \\
5458,263^{A}\end{array}$ & $\begin{array}{l}2438,588 \\
7156,928 \\
4797,758^{A}\end{array}$ & $\begin{array}{c}2441,579 \\
8791,860 \\
5616,719^{A}\end{array}$ & $\begin{array}{c}2491,655 \\
8598,914 \\
5525,284^{\mathrm{A}}\end{array}$ & $\begin{array}{c}2472,833^{a} \\
8236,177^{b} \\
-\end{array}$ \\
\hline $\begin{array}{l}\text { Eosinófilos } \\
\text { (valores absolutos mé- } \\
\text { dios por } \mu \text { l de sangue) }\end{array}$ & $\begin{array}{l}\text { Sadios }^{* *} \\
\text { Doentes } \\
\text { Médias }\end{array}$ & $\begin{array}{c}319,263^{\mathrm{Ab}} \\
519,375^{\mathrm{Aa}} \\
419,319\end{array}$ & $\begin{array}{c}295,645^{\mathrm{Ab}} \\
573,950^{\mathrm{Aa}} \\
434,798\end{array}$ & $\begin{array}{c}291,634^{\mathrm{Ab}} \\
1141,127^{\mathrm{Ba}} \\
716,380\end{array}$ & $\begin{array}{c}398,791^{\mathrm{Aa}} \\
481,998^{\mathrm{Aa}} \\
440,484\end{array}$ & $\begin{array}{c}326,378 \\
679,112 \\
-\end{array}$ \\
\hline $\begin{array}{l}\text { Linfócitos } \\
\text { (valores absolutos mé- } \\
\text { dios por } \mu \text { l de sangue) }\end{array}$ & $\begin{array}{l}\text { Sadios }^{* *} \\
\text { Doentes***} \\
\text { Médias }\end{array}$ & $\begin{array}{c}4433,776 \\
4842,791 \\
4638,283^{A}\end{array}$ & $\begin{array}{c}4554,998 \\
4502,522 \\
45528,760^{A}\end{array}$ & $\begin{array}{c}4225,909 \\
4352,515 \\
4289,212^{A}\end{array}$ & $\begin{array}{c}4105,603 \\
3973,234 \\
4039,418^{A}\end{array}$ & $\begin{array}{c}4330,071^{\mathrm{a}} \\
4417,765^{\mathrm{a}} \\
-\end{array}$ \\
\hline $\begin{array}{l}\text { Monócitos } \\
\text { (valores absolutos mé- } \\
\text { dios por } \mu \text { l de sangue) }\end{array}$ & $\begin{array}{l}\text { Sadios }^{b} \\
\text { Doentes } \\
\text { Médias }\end{array}$ & $\begin{array}{c}98,308 \\
275,615 \\
186,961^{\mathrm{A}}\end{array}$ & $\begin{array}{c}70,083 \\
417,011 \\
243,547^{A}\end{array}$ & $\begin{array}{c}63,132 \\
231,799 \\
147,465^{A}\end{array}$ & $\begin{array}{c}56,743 \\
273,494 \\
165,118^{A}\end{array}$ & $\begin{array}{c}72,066^{\mathrm{b}} \\
299,480^{\mathrm{a}} \\
-\end{array}$ \\
\hline $\begin{array}{l}\text { Plaquetas } \\
\text { (valores médios } \\
\text { por } \mu \text { l de sangue) }\end{array}$ & $\begin{array}{l}\text { Sadios }^{b} \\
\text { Doentes } \\
\text { Médias }\end{array}$ & $\begin{array}{c}435,610 \\
588,500 \\
512,055^{A}\end{array}$ & $\begin{array}{c}396,161 \\
513,133 \\
454,647^{A}\end{array}$ & $\begin{array}{c}406,045 \\
551,700 \\
479,373^{A}\end{array}$ & $\begin{array}{c}393,410 \\
520,415 \\
456,913^{A}\end{array}$ & $\begin{array}{c}407,807^{b} \\
543,437^{a} \\
-\end{array}$ \\
\hline
\end{tabular}

* G1 = menores do que 1 ano; G2 = de 1-3 anos; G3 = de 3-5 anos; G4 = mais de 5 anos. Médias na mesma linha, seguidas da mesma letra maiúscula, não diferem entre si pelo teste SNK $(P>0,05)$. Em cada parâmetro avaliado, médias, na mesma coluna, seguidas da mesma letra minúscula, não diferem entre si pelo teste SNK $(P>0,05) ;{ }^{* *} n=371 ;{ }^{* * *} n=56$.

por mecanismos medulares e extra-medulares, em conseqüência da depressão da atividade eritroblástica, liberação de citocinas pró-inflamatórias comumente verificadas no curso de doenças infecciosas (Sacher \& Mcphearson 2002) e pela deficiência nutricional associado à perda sanguínea decorrente de hemorragia nasal e

Quadro 8. Valores médios das proteínas totais, albumina e globulinas de ovinos sadios e portadores de conidiobolomicose, no Estado do Piauí, por estado sanitário e por grupo, segundo a faixa etária

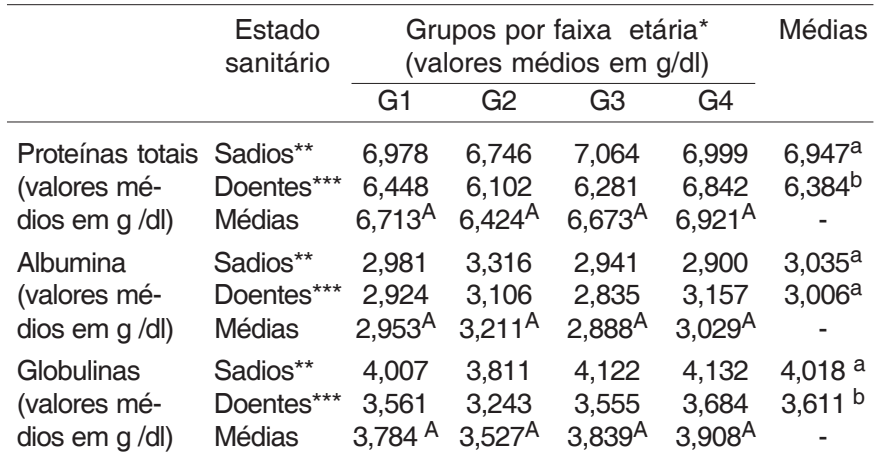

${ }^{*}$ G1 = menores do que 1 ano; G2 = de 1-3 anos; G3 = de 3-5 anos; G4 = mais de 5 anos. Médias na mesma linha, seguidas da mesma letra maiúscula, não diferem entre si pelo teste SNK $(P>0,05)$. Em cada parâmetro avaliado, médias, na mesma coluna, seguidas da mesma letra minúscula, não diferem entre si pelo teste SNK $(P>0,05) ;{ }^{* *} n=$ $371 ;{ }^{* \star *} \mathrm{n}=56$.
Quadro 9. Valores médios de magnésio, cálcio, fósforo e cloretos séricos de ovinos sadios e portadores de conidiobolomicose, no Estado do Piauí, por estado sanitário e por grupo, segundo a faixa etária

\begin{tabular}{|c|c|c|c|c|c|c|}
\hline & \multirow[t]{2}{*}{$\begin{array}{l}\text { Estado } \\
\text { sanitário }\end{array}$} & \multicolumn{4}{|c|}{$\begin{array}{l}\text { Grupos por faixa etária* } \\
\text { (valores em } \mathrm{mg} / \mathrm{dl} \text { ) }\end{array}$} & \multirow[t]{2}{*}{ Médias } \\
\hline & & G1 & G2 & G3 & G4 & \\
\hline & & $\begin{array}{c}2,304 \\
1,613 \\
1,959^{A}\end{array}$ & $\begin{array}{c}2,131 \\
1,714 \\
1,923^{\mathrm{A}}\end{array}$ & $\begin{array}{c}2,436 \\
1,745 \\
2,091^{\mathrm{A}}\end{array}$ & $\begin{array}{c}2,139 \\
1,653 \\
1,896^{A}\end{array}$ & $\begin{array}{l}253^{a} \\
681^{b} \\
-\end{array}$ \\
\hline $\begin{array}{l}\text { Cálcio } \\
\text { (valores } \\
\text { em mg/dl) }\end{array}$ & $\begin{array}{l}\text { Sadios**} \\
\text { Doentes } \\
\text { Médias }\end{array}$ & $\begin{array}{c}7,674 \\
3,653 \\
5,664^{\mathrm{A}}\end{array}$ & $\begin{array}{c}7,351 \\
3,744 \\
5,548^{A}\end{array}$ & $\begin{array}{c}7,775 \\
4,027 \\
5,901^{A}\end{array}$ & $\begin{array}{c}7,645 \\
3,878 \\
5,762^{A}\end{array}$ & $\begin{array}{c}7,611^{a} \\
3,825^{b} \\
-\end{array}$ \\
\hline em mg/dl) & $\begin{array}{l}\text { Sadios }^{\star *} \\
\text { Doentes }^{\star * *} \\
\text { Médias }\end{array}$ & $\begin{array}{c}4,100 \\
4,226 \\
4,163^{A}\end{array}$ & $\begin{array}{c}3,947 \\
5,096 \\
4,522^{A}\end{array}$ & $\begin{array}{c}3,875 \\
4,004 \\
3,940^{A}\end{array}$ & $\begin{array}{c}3,953 \\
4,582 \\
4,268^{A}\end{array}$ & $\begin{array}{l}969^{b} \\
477^{a} \\
-\end{array}$ \\
\hline $\begin{array}{l}\text { Cloretos } \\
\text { (valores } \\
\text { em mg/dl) }\end{array}$ & $\begin{array}{l}\text { Sadios }{ }^{* *} \\
\text { Doentes**} \\
\text { Médias }\end{array}$ & $\begin{array}{c}94,048 \\
97,851 \\
94,688^{A}\end{array}$ & $\begin{array}{c}89,618 \\
96,169 \\
90,690^{A}\end{array}$ & $\begin{array}{c}91,867 \\
90,676 \\
91,749^{A}\end{array}$ & $\begin{array}{c}90,439 \\
86,553 \\
90,067^{A}\end{array}$ & $\begin{array}{c}91,493^{a} \\
92,812^{a} \\
-\end{array}$ \\
\hline
\end{tabular}

* G1 = menores do que 1 ano; G2 = de 1-3 anos; G3 = de 3-5 anos; G4 $=$ mais de 5 anos. Médias na mesma linha, seguidas da mesma letra maiúscula, não diferem entre si pelo teste SNK $(P>0,05)$. Em cada parâmetro avaliado, médias, na mesma coluna , seguidas da mesma letra minúscula, não diferem entre si pelo teste SNK $(P>0,05) ;{ }^{* *} n=$ $371 ;{ }^{* * *} \mathrm{n}=56$.

anorexia presentes no curso da enfermidade. Essa anemia pode ser classificada como normocítica normocrômica, do tipo arregenerativa ou hipoplásica, comum em afecções crônicas e nas hemorragias, enquanto a medu- 
Quadro 10. Valores médios de glicose, uréia, creatinina, bilirrubina total (BT), bilirrubina direta (BD) e bilirrubina indireta $(\mathrm{BI})$ de ovinos sadios e portadores de conidiobolomicose, no Estado do Piauí, por estado sanitário e por grupo, segundo a faixa etária

\begin{tabular}{|c|c|c|c|c|c|c|}
\hline & \multirow{2}{*}{$\begin{array}{l}\text { Estado } \\
\text { sanitário }\end{array}$} & \multicolumn{4}{|c|}{ Grupos por faixa etária* } & \multirow[t]{2}{*}{ Médias } \\
\hline & & G1 & G2 & G3 & G4 & \\
\hline $\begin{array}{l}\text { Glicose } \\
\text { (valores mé- } \\
\text { dios em mg/dl) }\end{array}$ & & $\begin{array}{r}40,75 \\
30,8 \\
35,7\end{array}$ & $\begin{array}{c}41,852^{A a} \\
29,326^{A b} \\
35,454\end{array}$ & $\begin{array}{r}36,38 \\
44,46 \\
40,4\end{array}$ & $\begin{array}{c}40,692^{\mathrm{ABa}} \\
36,877^{\mathrm{Aa}} \\
38,785\end{array}$ & a \\
\hline Uréia & & $\begin{array}{r}37,928 \\
31,674 \\
34,801 \mathrm{~A}\end{array}$ & $\begin{array}{c}37,012 \\
37,837 \\
37,425^{A}\end{array}$ & & $\begin{array}{r}38 \\
37 \\
37\end{array}$ & $\begin{array}{c}37,327^{a} \\
35,248^{a} \\
-\end{array}$ \\
\hline & & $\begin{array}{c}0,815 \\
0,708 \\
0,762^{A}\end{array}$ & & & $\begin{array}{r}0,6 \\
0,7\end{array}$ & $831^{a}$ \\
\hline $\begin{array}{l}\text { BT } \\
\text { (valores mé- } \\
\text { dios em mg/dl) }\end{array}$ & & $\begin{array}{r}0,041 \\
0,087 \\
0,064^{A}\end{array}$ & $\begin{array}{c}0,074 \\
0,050^{\mathrm{A}}\end{array}$ & 0,0 & $\begin{array}{l}0,0 \\
0,0\end{array}$ & $\begin{array}{l}, 042^{b} \\
-083^{a} \\
-\end{array}$ \\
\hline $\begin{array}{l}\text { BD } \\
\text { (valores mé- } \\
\text { dios em mg/dl) }\end{array}$ & $\begin{array}{l}\text { Sadios**} \\
\text { Doentes }^{* * *} \\
\text { Médias }\end{array}$ & $\begin{array}{c}0,016 \\
0,028 \\
0,022^{A}\end{array}$ & $\begin{array}{c}0,017 \\
0,031 \\
0,024^{\mathrm{A}}\end{array}$ & $\begin{array}{c}0,020 \\
0,030 \\
0,025^{A}\end{array}$ & $\begin{array}{c}0,016 \\
0,041 \\
0,029^{A}\end{array}$ & $\begin{array}{l}017^{b} \\
033^{a}\end{array}$ \\
\hline $\begin{array}{l}\text { Bl } \\
\text { (valores mé- } \\
\text { dios em mg/dl) }\end{array}$ & $\begin{array}{l}\text { Sadios**} \\
\text { Doentes } \\
\text { Médias }\end{array}$ & $\begin{array}{c}0,025 \\
0,059 \\
0,042^{A}\end{array}$ & $\begin{array}{l}0,028 \\
0,043 \\
0,036^{A}\end{array}$ & $\begin{array}{c}0,026 \\
0,055 \\
0,041^{A}\end{array}$ & $\begin{array}{c}0,021 \\
0,035 \\
0,028^{A}\end{array}$ & $\begin{array}{l}0,025^{b} \\
0,0349^{a}\end{array}$ \\
\hline
\end{tabular}

${ }^{*} \mathrm{G} 1$ = menores do que 1 ano; G2 = de 1-3 anos; G3 = de 3-5 anos; G4 $=$ mais de 5 anos. Médias na mesma linha, seguidas da mesma letra maiúscula, não diferem entre si pelo teste SNK $(P>0,05)$. Em cada parâmetro avaliado, médias, na mesma coluna, seguidas da mesma letra minúscula, não diferem entre si pelo teste SNK $(P>0,05) ;{ }^{* \star} n=$ $371 ;{ }^{* \star *} n=56$.

la ainda não iniciou a sua resposta aos fatores desencadeantes (Sacher \& Mcpherson 2002, Lorenzi 2003).

A média geral de leucócitos nos animais doentes foi significativamente superior a dos sadios (Quadro 6), demonstrando que a conidiobolomicose induziu a uma leucocitose. A literatura não faz referências a achados hematológicos de animais acometidos por essa enfermida- de, porém é sabido que há leucocitose em infecções fúngicas (Gorina 1996, Lima et al. 2001). Nas contagens diferenciais de leucócitos (Quadro 7), os animais acometidos de conidiobolomicose apresentaram neutrofilia, com elevação dos bastonetes, evidenciando um discreto desvio nuclear neutrofílico à esquerda regenerativo e, também, uma elevação acentuada de segmentados, como é comum nos processos inflamatórios e infecciosos de etiologia fúngica (Jain 1993, Lorenzi 2003).

A discreta eosinofilia observada em alguns animais doentes do grupo G3, sobretudo os portadores de pneumonia, é um achado compatível com quadros pneumônicos (Sacher \& McPherson 2002, Kerr 2003). Nos animais enfermos houve, também, leve monocitose (Quadro 7), indicando uma tendência à cronificação do processo. Foi observada linfopenia nos animais doentes havendo diferença significativa entre os dois grupos. Entretanto, essa diferença foi apenas nos valores relativos dos linfócitos e a conversão para valores absolutos demonstrou que essas células mantiveram-se dentro da faixa da normalidade. A plaquetose observada nos ovinos enfermos (Quadro 7) pode estar relacionada ao sangramento nasal observado no curso da doença, associada ao componente infeccioso, considerando-se que doenças hemorrágicas e infecciosas desencadeiam trombocitose (Lima et al. 2001, Kerr 2003).

Assim, fazendo-se uma avaliação global dos achados do hemograma, constatou-se que ocorreu uma alteração na resposta leucocitária fisiológica da espécie ovina, nos animais portadores de conidiobolomicose, visto que a relação neutrófilo:linfócito em ruminantes, é da ordem de 0,5 (Taylor 2000) ou de 30:70 (Kerr 2003). Essa relação situou-se entre 0,55 e 0,61 nos grupos de animais sadios e ficou entre 1,59 e 2,02 nos grupos de animais doentes. Portanto, a infecção fúngica desencadeou elevação da relação neutrófilo:linfócito em torno de três vezes.

Os menores teores de proteínas totais séricas obser-

Quadro 11. Valores médios de aspartato aminotransferase (AST), fosfatase alcalina (FA) e gama-glutamiltransferase (GGT) de ovinos sadios e portadores de conidiobolomicose, no Estado do Piauí, por estado sanitário e por grupo, segundo a faixa etária

\begin{tabular}{|c|c|c|c|c|c|c|}
\hline & \multirow{2}{*}{$\begin{array}{c}\text { Estado } \\
\text { sanitário }\end{array}$} & \multicolumn{4}{|c|}{ Grupos por faixa etária* (valores em UI/Litro) } & \multirow[t]{2}{*}{ Médias } \\
\hline & & G1 & G2 & G3 & G4 & \\
\hline $\begin{array}{l}\text { AST } \\
\text { (valores médios } \\
\text { em Ul/Litro) }\end{array}$ & $\begin{array}{l}\text { Sadios }^{\star *} \\
\text { Doentes } \\
\text { Médias }\end{array}$ & $\begin{array}{c}267,893 \\
\text { * } 317,706 \\
292,800^{A}\end{array}$ & $\begin{array}{c}266,435 \\
407,278 \\
336,857^{A}\end{array}$ & $\begin{array}{c}249,022 \\
338,000 \\
293,511^{A}\end{array}$ & $\begin{array}{c}257,375 \\
275,455 \\
266,415^{A}\end{array}$ & $\begin{array}{c}260,181^{b} \\
334,610^{a} \\
-\end{array}$ \\
\hline $\begin{array}{l}\text { FA } \\
\text { (valores em } \\
\text { Ul/Litro) }\end{array}$ & $\begin{array}{l}\text { Sadios }^{\star \star} \\
\text { Doentes } \\
\text { Médias }\end{array}$ & $\begin{array}{c}52,366 \\
40,478 \\
46,422^{A}\end{array}$ & $\begin{array}{c}47,399 \\
32,428 \\
39,914 \text { A }\end{array}$ & $\begin{array}{c}51,022 \\
41,433 \\
46,228^{A}\end{array}$ & $\begin{array}{c}42,682 \\
31,034 \\
36,858^{A}\end{array}$ & $\begin{array}{c}48,367^{a} \\
36,346^{b} \\
-\end{array}$ \\
\hline $\begin{array}{l}\text { GGT } \\
\text { (valores em } \\
\text { Ul/Litro) }\end{array}$ & $\begin{array}{l}\text { Sadios }^{\star *} \\
\text { Doentes } \\
\text { Médias }\end{array}$ & $\begin{array}{c}46,041 \\
\times \quad 55,911 \\
50,976 \mathrm{~A}\end{array}$ & $\begin{array}{c}50,107 \\
58,274 \\
54,190^{A}\end{array}$ & $\begin{array}{c}50,990 \\
59,117 \\
55,054 \mathrm{~A}\end{array}$ & $\begin{array}{c}52,016 \\
60,935 \\
56,476{ }^{A}\end{array}$ & $\begin{array}{c}49,789^{b} \\
58,559^{a} \\
-\end{array}$ \\
\hline
\end{tabular}

* G1 = menores do que 1 ano; G2 = de 1-3 anos; G3 = de 3-5 anos; G4 = mais de 5 anos. Médias na mesma linha, seguidas da mesma letra maiúscula, não diferem entre si pelo teste SNK $(P>0,05)$. Em cada parâmetro avaliado, médias, na mesma coluna, seguidas da mesma letra minúscula, não diferem entre si pelo teste SNK $(P>0,05) ;{ }^{* \star} n=371 ;{ }^{* \star \star} n=56$. 
vados nos animais doentes (Quadro 8) podem ter sido conseqüência das perdas sangüíneas, deficiências nutricionais e debilitação orgânica, situações que podem ocasionar redução das proteínas (Kerr 2003). Considerando que não se constataram diferenças nos teores de albumina entre animais doentes e animais sadios (Quadro 8), a redução dos teores de globulinas foi, portanto, o fator responsável pela diminuição das proteínas totais nos animais enfermos. Isto sugere que a doença gera imunodepressão, embora bastante discreta considerando o curso não muito longo, pois mesmo tendo havido diferença significativa entre sadios e doentes os valores de globulinas e proteínas totais ainda permanecem dentro da faixa considerada normal por alguns autores (Kaneko et al. 1997). Além disso, a relação A:G nos enfermos foi muito próxima da encontrada nos hígidos. Decréscimos na fração globulínica podem ser observados em processos infecciosos e doenças debilitantes em geral (Gorina 1996, Kerr 2003).

A literatura não faz referência a teores de eletrólitos em animais clinicamente afetados por conidiobolomicose. A redução dos níveis de magnésio (Quadro 9) nos animais doentes pode ser explicada por deficiência deste mineral conseqüente à inanição observada no curso da enfermidade. Os animais afetados apresentaram, também, diminuição dos níveis de $\mathrm{Ca}$ quando comparados com os sadios (Quadro 9).

Hipocalcemia ocorre em enfermidades debilitantes e em estados de inanição (Lima et al. 2001, Kerr 2003), sendo esta última situação a provável causa da redução dos teores de cálcio nos animais enfermos.

Contrariamente ao que ocorreu com o cálcio e magnésio, os animais doentes mostraram teores de fósforo sérico superiores aos sadios (Quadro 9). Esta elevação nos teores de fósforo pode ser atribuída à relação inversa com o cálcio, comumente encontrada no curso de algumas patologias graves (Gorina 1996).

Três grupos (G1, G2, e G3) de ovinos doentes apresentaram teores de glicose significativamente inferiores aos sadios (Quadro 10). A redução da glicemia nestes grupos de animais doentes pode estar associada à inanição prolongada e esgotamento das reservas corpóreas (Sacks 1998), sendo que os animais mais novos mostraram-se mais sensíveis aos efeitos da deficiência alimentar.

As dosagens de uréia e creatinina (Quadro 10) permitiram observar a ausência de danos no funcionamento renal (Duncan et al. 1994, Kerr 2003) o que é compatível com as observações clínicas.

Os animais com conidiobolomicose apresentaram teores de bilirrubina total e bilirrubina direta (Quadro 10) superiores aos animais sadios, o que pode ser atribuídas ao jejum prolongado (Kerr 2003), uma vez que 100\% dos animais acometidos demonstraram anorexia, além da anemia, que também pode ser considerada como agente indutor de hiperbilirrubinemia (Lorenzi 2003).

Os ovinos afetados apresentaram, também, teores de AST e gama-GT superiores aos sadios (Quadro 11), en- quanto que os valores de FA foram menores nos animais doentes do que nos sadios (Quadro 11). De uma maneira geral, a literatura considera que elevações de AST podem indicar disfuncionalidade hepática em ruminantes, desde que correlacionados com outras dosagens. A literatura faz referência à ocorrência de aumento dos teores de AST em cães portadores de conidiobolomicose (Bauer et al. 1997), embora essa alteração tenha sido atribuída ao efeito da terapia empregada, o que não aconteceu neste estudo, cujos relatos são de animais que não receberam tratamento. A elevação da FA é indicativa de dano hepatobiliar, sugerindo colestase (Duncan et al. 1994), o que não é o caso dos animais integrantes deste estudo, que apresentaram valores FA reduzidos. A gama-GT parece estar associada a quadros hepáticos crônicos e tende a aumentar quando ou outras enzimas indicativas de disfuncionalidade hepática estão baixas (Kerr 2003). A sua elevação associada à redução da FA, pode significar que a enfermidade gerou algum grau de disfunção hepática, mesmo em grau não perceptível ao exame clínico e hemograma.

Os resultados deste trabalho podem ser utilizados para estudos experimentais da doença, em ensaios com tratamentos e para identificar casos precoces da enfermidade que não apresentem sinais clínicos. Apesar da conidiobolomicose ovina apresentar curso clinico de uma a cinco semanas (Silva et al. 2007b, Riet-Correa et al. 2008), a cronicidade observada em lesões histológicas sugere que ao aparecem os sinais clínicos o animal já está doente há algum tempo, provavelmente por serem as lesões indolores (Riet-Correa et al. 2008). A detecção precoce desses casos permitiria um tratamento com maiores possibilidades de cura. Por outro lado, os valores da bioquímica sanguínea encontrados em 371 ovinos deslanados hígidos podem ser utilizados como valores normais para este tipo de ovinos na região semi-árida do Brasil.

Agradecimentos.- À CAPES pela bolsa de doutorado concedida ao primeiro autor e ao CNPq (Proc. 48.0127/00-0) pelo apoio financeiro.

\section{REFERÊNCIAS}

Arruda L.P., Boabaid F.M., Ferreira E.V., Dutra V., Silva M.C., Nakazato L., Tartari S.L., Oliveira P.M., Fontana D. \& Colodel E.M. 2007. Conidiobolomicose em ovinos no Estado de Mato Grosso. XIII Encontro Nacional de Patologia Veterinária (Enapave), Campo Grande, MS, in CD-ROM.

Bauer R.W., Lemarié S.L. \& Roy A.F. 1997. Oral conidiobolomycosis in a dog. Vet. Dermatol. 8:115-120.

Berquó E.S., Souza J.M.P. \& Gottlieb S.L.D. 1981. Bioestatística. EPU, São Paulo. 323p.

Carrigan M.J., Small A.C. \& Perry G.H. 1992. Ovine nasal zygomycosis caused by Conidiobolus incongruus. Aust. Vet. J. 69:237-240.

Duncan J.R., Prasse K.W. \& Mahaffey E.A. 1994. Veterinary Laboratory Medicine. 3rd ed. Elsevier, Ames. 299p.

French R.A. \& Ashworth C.D. 1994. Zygomycosis caused by Conidiobolus coronatus in a llama (Llama glama). Vet. Pathol. 31:120122.

Furlan F.H., Borelli V., Lucioli J., Fonteque J.H. \& Gava A. 2007. Granuloma fúngico nasal em ovinos no Estado de Santa Catarina. 
XIII Encontro Nacional de Patologia Veterinária (Enapave), Campo Grande, MS, in CD-ROM.

Gorina A.B. 1996. Exames de sangue, p.121-172. In: Gorina A.B. (Ed.), Hematologia Clínica. MEDSI, Rio de Janeiro.

Guedes M.L.S. \& Guedes J.S. 1988. Bioestatística para Profissionais de Saúde. CNPq, Brasília. 201p.

Jain N.C. 1993. Essential of Veterinary Hematology. Lea and Febiger, Philadelphia. $417 \mathrm{p}$.

Johnston M.J., Soerensen B., Saliba A.M., Lacaz C.G., Bela Neto J. \& Cruz J.M. 1967. Ficomicose em muar: isolamento de Entomophthora coronata. Arqs Inst. Biológico, São Paulo, 34:51-58.

Kaneko J.J., Haarvey J.W. \& Bruss M.L. 1997. Clinical Biochemistry of Domestic Animals. 5th ed. Academic Press, New York, p.345-358.

Kerr M.G. 2003. Exames Laboratoriais em Medicina Veterinária. Bioquímica Clínica e Hematologia. $2^{\text {a }}$ ed. Roca, São Paulo. 436p.

Ketterer P.J., Kelly M.A. \& Connole M.D. 1992. Rhinocerebral and nasal zygomycosis in sheep caused by Conidiobolus incongrus. Aust. Vet. J. 69(4):85-87.

King D.S. \& Jong S.C. 1976. Identity of the etiological agent of the first deep entomophthoraceus infection of man in the United States. Mycologia 5:181-183.

Lacaz I.G. 1981. Estudo das zigomicoses por Entomophthorales. Dissertação de Mestrado em Medicina Tropical, Centro de Ciências da Saúde, Universidade Federal de Pernambuco, Recife. 49p.

Lima A.O., Soares J.B., Greco J.B., Galizzi J. \& Cançado J.R. 2001. Química do sangue, p.2.1-2.66. In: Lima A.O., Soares J.B., Greco J.B., Galizzi J. \& Cançado J.R. (Ed.), Métodos de Laboratório Aplicados à Clínica. $8^{\mathrm{a}}$ ed. Guanabara Koogan, Rio de Janeiro.

Lorenzi T.F. 2003. Anemias, p.193-288. In: Lorenzi T.F. (Ed.), Manual de Hematologia, Propedêutica e Clínica. $3^{\underline{a}}$ ed. MEDSI, Rio de Janeiro.

Medway W. 1980. Some bacterial and mycotic diseases of marine mammals. J. Am. Vet. Med. Assoc. 177:831-834.

Mendoza L. \& Alfaro A.A. 1985. Equine subcutaneous zygomycosis in Costa Rica. Mykosen 28:545-549.

Miller R.I. 1983. Equine phycomycosis. Comp. Cont. Educ. Pract. Vet. 5:472-478.

Moll H.D., Schumacher J. \& Hoover T.R. 1992. Entomophtoramycosis conidiobolae in a llama. J. Am. Vet. Assoc. 200:969-970.

Morris M., Ngeleka M., Adogwa A.O., Lalla G., St-Germain G. \& Higgins R. 2001. Rhinocerebral zygomycosis in a sheep. Can. Vet. J. 42:227-228.

Moss D.W. \& Handerson A.R. 1998. Enzimas, p.275-325. In: Burtis C.A. \& Ashwood E.R. (Ed.), Fundamentos de Química Clínica. 4aㅡ ed. Guanabara Koogan, Rio de Janeiro.

Pinheiro Junior G.C. 1973. A idade dos ovinos e a sua determinação, p.2729. In: Pinheiro Junior G.C. (Ed.), Ovinos do Brasil. Itatiaia, Belo Horizonte.
Prabhu R.M. \& Patel R. 2004. Mucormycosis and entomophthoramycosis: A review of the clinical manifestations, diagnosis and treatment. Eur. Soc. Clin. Microb. Infec. Dis. 10 (Suppl.1):31-47.

Riet-Correa F., Dantas A.F.M., Azevedo E.O., Simões S.D.V., Silva S.M.S., Vilela R. \& Mendoza L. 2008. Outbreaks of rhinofacial and rhinopharyngeal zygomycosis in sheep in Paraíba, northeastern Brazil. Pesq. Vet. Bras. 27(4):184-190.

Roy A.D. \& Cameron H.M. 1972. Rhinophycomycosis entomophtorae occurring in a chimpanzee in the wild in East Africa. Am. J. Trop. Med. Hyg. 21:234-237.

Rippon J.M. 1988. Medical Mycology: The pathogenic fungi and pathogenic Actinomycetes. $3^{\text {rd }}$ ed. W.B. Saunders, Philadelphia. 797p.

Sacher R.A. \& McPherson R.A. 2002. Hematologia, p.431-441. In: Sacher R.A. \& McPherson R.A. (Ed.), Interpretação Clínica dos Exames Laboratoriais. $11^{a}$ ed. Manole, São Paulo.

Sacks D.B. 1998. Glicídeos, p.341-363. In: Burtis C.A. \& Ashwood E.R. (Ed.), Fundamentos de Química Clínica. 4aㅡ ed. Guanabara Koogan, Rio de Janeiro.

Sampaio I.B.M. 1998. Estatística Aplicada à Experimentação Animal. Fundação de Ensino e Pesquisa em Medicina Veterinária e Zootecnia, Belo Horizonte. 221p.

Silva S.M.M.S., Castro R.S., Costa F.A.L., Vasconcelos A.C., Batista M.C.S., Riet-Correa F. \& Carvalho E.M.S. 2007a. Conidiobolomycosis in sheep in Brazil. Vet. Pathol. 44:314-319.

Silva S.M.M.S., Castro R.S., Costa F.A.L., Vasconcelos A.C., Batista M.C.S., Riet-Correa F. \& Carvalho E.M.S. 2007b. Conidiobolomicose em ovinos no Brasil: epidemiologia e sinais clínicos em 25 rebanhos. Pesq. Vet. Bras. 27:184-190.

Stephens C.P. \& Gibson J.A. 1997. Disseminated zygomycosis caused by Conidiobolus incongruus in a deer. Aust. Vet. J. 75:358-360.

Souza Filho L.G., Nico M.M.S. \& Salebian A. 1992. Entomoftoromicose rinofacial por Conidiobolus coronatus. Registro de um caso tratado com sucesso pelo fluoconazol. Revta Inst. Med. Trop., São Paulo, 34(5):483-487.

Tadano T., Paim N.P., Hueb M. \& Fontes C.J.F. 2005. Entomoftoromicose (zigomicose) causada por Conidiobolus coronatus em Mato Grosso (Brasil): relato de caso. Revta Soc. Bras. Med. Trop. 38(2):188190.

Taylor J.A. 2000. Leukocyte response in Ruminants, p.391-404. In: Feldman B.F., Zinkl J.G. \& Jain N.C. (Ed.), Schalm's Veterinary Hematology. 5th ed. Lippincott Williams and Wilkins, Baltimore.

Ueno H. \& Gonçalves P.C. 1998. Manual para Diagnóstico das Helmintoses de Ruminantes. $4^{\mathrm{a}}$ ed. Japan International Cooperation Agency, Tokyo. 143p.

Zamos D.T., Schumacher J. \& Loy J.K. 1996. Nasopharyngeal conidiobolomycosis in a horse. J. Am. Vet. Assoc. 208:100-101. 